Article

\title{
In Vitro and in Field Response of Different Fungicides against Aspergillus flavus and Fusarium Species Causing Ear Rot Disease of Maize
}

\author{
Mario Masiello *, Stefania Somma, Veronica Ghionna, Antonio Francesco Logrieco and \\ Antonio Moretti $(D)$ \\ Institute of Sciences of Food Production, Research National Council (ISPA-CNR), Via Amendola 122/O, \\ 70126 Bari, Italy; stefania.somma@ispa.cnr.it (S.S.); veronica.ghionna@ispa.cnr.it (V.G.); \\ antonio.logrieco@ispa.cnr.it (A.F.L.); antonio.moretti@ispa.cnr.it (A.M.) \\ * Correspondence: mario.masiello@ispa.cnr.it
}

Received: 23 November 2018; Accepted: 24 December 2018; Published: 1 January 2019

check for updates

\begin{abstract}
Aspergillus flavus, the main aflatoxin $\mathrm{B}_{1}$ producing fungal species, Fusarium graminearum, a deoxynivalenol producer, and the fumonisin-producing species F. proliferatum and F. verticillioides are the main toxigenic fungi (TF) that colonize maize. Several strategies are available to control TF and related mycotoxins, such as chemical control. However, there is poor knowledge on the efficacy of fungicides on maize plants since few molecules are registered. The sensitivity of F. graminearum, F. proliferatum, F. verticillioides, and A. flavus to eleven fungicides, selected based on their different modes of action, was evaluated in both in vitro assays and, after selection, in the field. In vitro, demethylation inhibitors (DMI) showed excellent performances, followed by thiophanate-methyl and folpet. Among the succinate dehydrogenase inhibitors (SDHI), isopyrazam showed a higher effectiveness against Fusarium species than boscalid, which was ineffective against Fusarium, like the phenyl-pyrrole fludioxonil. Furthermore, both SDHIs and fludioxonil were more active against $A$. flavus than Fusarium species. In field trials, prothioconazole and thiophanate-methyl were confirmed to be effective to reduce F. graminearum (52\% and $48 \%$ ) and F. proliferatum contamination ( $44 \%$ and $27 \%$ ). On the other hand, prothioconazole and boscalid could reduce $A$. flavus contamination at values of $75 \%$ and $56 \%$, respectively.
\end{abstract}

Keywords: prothioconazole; boscalid; fludioxonil; SDHI-resistance; Demethylation Inhibitors; maize ear rot disease control

Key Contribution: DMIs and Methyl Benzimidazole Carbamates (MBCs) showed the best inhibition activity for Fusarium species and Aspergillus flavus, in vitro. Fusarium species and $A$. flavus exhibited different response to fungicides. SDHIs are effective against $A$. flavus but ineffective for Fusarium species. The effectiveness of fungicides showing the best performance in vitro, was confirmed in field conditions. The use of fungicide mixture is the best strategy to control toxigenic fungi on maize.

\section{Introduction}

Cereals represent the most important crops providing the main carbohydrate source in human and livestock diets. Among cereals, maize is the first cultivated cereal worldwide [1]. However, under specific pedoclimatic conditions, abiotic and biotic stresses could cause huge economic and productive losses to maize cultivation. Among the fungal genera, Ustilago, Fusarium, and Aspergillus can appear from flowering stage to harvest time and are mainly associated to ear diseases [2-9]. In particular, great concern is caused by the diseases caused by mycotoxigenic species such as those belonging to Fusarium and Aspergillus genera. These species can contaminate maize kernels at maturity and 
produce several mycotoxins that can accumulate in the final products $[10,11]$. The trichothecenes deoxynivalenol (DON) and nivalenol (NIV), both well-known inhibitors of protein synthesis [12], the polyketide-derived fumonisins (FBs), associated with several animal and human diseases, the hestrogenic compound zearalenone (ZEA), and the carcinogenic aflatoxins are the major toxins detected in maize products [13-15].

Among maize crop diseases, the so called "Fusarium maize ear rot" (FER), caused by a complex of Fusarium species (e.g., Fusarium graminearum Schwäbe, Fusarium proliferatum (Matsushima) Nirenberg, and Fusarium verticillioides (Saccardo) Nirenberg), is very common in all maize cultivated areas [11]. Furthermore, Aspergillus species, occurring on maize kernels both in preharvest and during storage, also represent a serious problem since they cause high productive losses. Finally, since they can accumulate their mycotoxins in colonized tissues, and these mycotoxins are stable during food and feed processing procedure, these diseases have a significant economic impact and pose a serious risk for animal and human health [16-19].

Fusarium species can colonize maize in a wide range of climatic areas, and can alternate in the colonization of maize plants. In particular, while F. graminearum, the highest producing species of DON, NIV, and ZEA, better adapts to temperate geographic areas; F. proliferatum and F. verticillioides, representing the most important FBs producers [12], colonize maize grown in geographical areas with higher temperatures.

Fumonisins are mycotoxins often detected in association with fusaric acid, moniliformin, beauvericin, and fusaproliferin [10,20]. In central Europe, F. verticillioides is isolated mainly in co-occurrence with F. subglutinans and F. temperatum, while in southern Europe the spread of $F$. verticillioides is reinforced by the widespread presence of $F$. proliferatum, capable of producing $\mathrm{FB}_{1}$, moniliformin, beauvericin, and fusaproliferin [10].

Aspergillus flavus, the most important worldwide species able to produce aflatoxins on maize, colonizes this crop mostly when water stress and high temperature occur. Aspergillus flavus is commonly spread in tropical areas, however, due to climatic changes, this species is considered an emerging problem in several areas of Europe [21].

There is an urgent need to control these mycotoxigenic fungi on maize since the concern caused by their occurrence is growing worldwide $[19,22]$.

According to the new strategies of integrated pest management (IPM), several agronomic, genetic, biological techniques, and agricultural practices are now available to prevent or limit fungal diseases and related mycotoxin accumulation. The use of new hybrids and the control of the European corn borer can contribute to reduce Fusarium and FB contamination [23,24]. Also, the sowing time was shown to have a significant impact in the reduction of FB contamination [25]. In recent decades, several researches, encouraged by European Union, focused on biological control strategies effective in reducing mycotoxigenic fungi in the field and their mycotoxins [26]. However, chemical control is still considered a key tool to limit the fungal diseases on many important food crops, such as the small cereals, where, for the direct control of Fusarium Head Blight (FHB), spraying fungicides at flowering has been included among good agricultural practices [27].

Nowadays, the chemical control of fungal pathogens can be achieved by several different target site fungicides, discriminable for their mode of action. According to IPM strategies schedules, fungicides with different modes of action can be used in mixture or in an alternating regime on the same crop. The most recent target site fungicides are the succinate dehydrogenase inhibitors (SDHIs), in addition to the well-known phenyl-pyrroles (PP fungicides), that affect the fungal osmotic signal transduction cascade and pathogen osmoregulation (fludioxonil is the most known "compound"), and to the benzimidazole carbamates and the demethylation inhibitors fungicides (DMIs), that affect sterol biosynthesis in membranes.

DMIs and PPs are considered the most effective molecules registered nowadays to control fungal diseases caused by ascomycetes fungi, and also thought to be reliable on some cereal crops, where they are registered. 
However, poor knowledge on the efficacy of fungicides to control fungal and mycotoxins contamination on maize, is available [28]. Furthermore, the occurrence of field isolates resistant to fungicides [29-32] and the need to reduce chemical residues on the final products at harvest could make it more difficult the management of fungal diseases.

The present work aimed to (a) evaluate the in vitro sensitivity of F. graminearum, F. proliferatum, F. verticillioides, and A. flavus, the most toxigenic fungal species occurring on maize, towards 11 fungicides currently used on several crops, since they are representative of different modes of action and, based on in vitro results, (b) test the most effective fungicides on maize plants grown in field.

Our final goals were (a) to improve the knowledge about the effectiveness of the most important molecules available on market, to control main mycotoxigenic fungi involved in maize ear rot and (b) to obtain useful information for the registration of chemical compounds on maize crop.

\section{Results}

\subsection{In Vitro Colony Growth Inhibition}

The mycelia growth inhibition was evaluated at 3, 5, 7, and 10 days of incubation. The mean values of each fungal species, based on three strains for each species, at 10 days of incubation are reported in Figure 1. The total data of the experiment are reported in Supplementary files (Tables S1-S4).

\subsubsection{DMIs}

All DMIs showed an excellent activity to inhibit mycelial growth, up to 10 days of incubation.

In particular, prothioconazole and prochloraz completely inhibited the colony growth of all fungal strains at the three concentrations tested, as shown in Figure 1.

\section{Metconazole}

All Fusarium and A. flavus strains tested were inhibited by metconazole at the two highest doses (90 and $9 \mathrm{mg} \mathrm{L}^{-1}$ ); with the exception of $A$. flavus ITEM 8095 strain (inhibition value of $90 \%$ after 10 days of incubation, Table S4). However, at the lowest concentration $\left(0.9 \mathrm{mg} \mathrm{L}^{-1}\right)$, a different response to metconazole was observed among fungal genera (Figure 1). Fusarium species showed higher inhibition mean value (87\%) than A. flavus strains (53\%).

\section{Propiconazole}

The highest propiconazole concentration $\left(250 \mathrm{mg} \mathrm{L}^{-1}\right)$ inhibited completely all $F$. verticillioides and A. flavus strains. Fusarium proliferatum was completely inhibited for a single strain (ITEM 16031), while the two other strains tested had a mean of inhibition of $96 \%$ (Table S4). Fusarium graminearum showed mean value of $98 \%$ (Figure 1). At the two lowest concentrations of propiconazole, a great variability was observed among fungal species. In particular, F. verticillioides was sensitive, with inhibition values of $86 \%$ at the lowest concentration (Figure 1), while F. graminearum, at the same concentration, was inhibited of $41 \%$. The two species F. proliferatum and A. flavus showed the same sensitive profile, going through approximately 60,80 , to $100 \%$ at the increasing concentrations.

\section{Tebuconazole}

Tebuconazole completely inhibited all strains tested at the highest concentration $\left(320 \mathrm{mg} \mathrm{L}^{-1}\right)$, up to 10 days of incubation (Table S4), with the exception of the two F. graminearum strains ITEM 126 (inhibition of 93\%) and ITEM 6352 (inhibition of 98\%) and F. proliferatum ITEM 12072 (inhibition of $94 \%)$. A greater variability was observed among fungal species at lower concentrations: F. verticillioides strains were almost completely inhibited (94\%), while F. proliferatum, F. graminearum, and A. flavus showed lower inhibition values: $77 \%, 67 \%$, and $64 \%$, respectively (Figure 1 ). 


\section{Difenoconazole}

Among DMIs, difenoconazole showed the lowest effectiveness. However, after 10 days of incubation, at the highest concentration tested $\left(250 \mathrm{mg} \mathrm{L}^{-1}\right), F$. verticillioides and A. flavus strains were completely inhibited, while $F$. graminearum and F. proliferatum had mean values of inhibition of $77 \%$ and $90 \%$, respectively. At the lowest concentration $\left(2.5 \mathrm{mg} \mathrm{L}^{-1}\right), F$. verticillioides showed a higher inhibition value (82\%) than F. graminearum (60\%), F. proliferatum (67\%), and A. flavus (52\%).

\subsubsection{SDHIs}

\section{Boscalid}

Boscalid completely inhibited A. flavus mycelial growth at the three concentration tested (500, $50,5 \mathrm{mg} \mathrm{L}^{-1}$ ), up to 10 days (Figure 1). After three days of incubation (Table S1), Fusarium species were slightly influenced by the highest concentration (inhibition value up to $30 \%$ ). However, after 10 days of incubation, all Fusarium species were able to grow in presence of boscalid even at highest concentrations (inhibition values from 0 to $7 \%$ ).

\section{Isopyrazam}

Both Fusarium and Aspergillus, except F. graminearum (inhibition value of 93\%), were completely inhibited by isopyrazam at the highest concentration $\left(200 \mathrm{mg} \mathrm{L}^{-1}\right)$ after 10 days of incubation (Figure 1 ). At the two lowest concentrations ( 20 and $2 \mathrm{mg} \mathrm{L}^{-1}$ ), a different response was observed among the two fungal genera. Fusarium graminearum strains were not affected by the lowest concentration, growing as on unamended control medium, while F. verticillioides and F. proliferatum showed inhibition values ranging between $2 \%$ and $13 \%$, respectively. On media amended with $20 \mathrm{mg} \mathrm{L}^{-1}$, all Fusarium species were inhibited with mean values ranging between $24 \%$ (F. graminearum ITEM 126 ) and $49 \%$ (F. verticillioides ITEM 12043). Aspergillus flavus was more influenced than the Fusarium species, showing inhibition values of $79 \%$ and $89 \%$, at the two lowest concentrations.

In summary, both SDHI compounds, boscalid and isopyrazam, caused a higher inhibition towards A. flavus than towards all Fusarium species tested.

\subsubsection{PPs}

\section{Fludioxonil}

Fludioxonil showed a lower effectiveness compared to other fungicides; after three days of incubation, only F.graminearum strains were completely inhibited by the three concentrations tested (50, 5, and $\left.0.5 \mathrm{mg} \mathrm{L}^{-1}\right)$, as reported in Table S1. In F. verticillioides species, increasing concentrations of fludioxonil were not positively correlated with inhibition values: F. verticillioides ITEM 12052 showed inhibition values of $80 \%, 70 \%$, and $74 \%$ on media amended with $0.5,5$, and $50 \mathrm{mg} \mathrm{L}^{-1}$ of fludioxonil, respectively; F. verticillioides ITEM 12044 showed the same response of ITEM 12052, with inhibition of $79 \%, 72 \%$, and $80 \%$. On the other hand, F. verticillioides ITEM 12043 was inhibited of about $70 \%$ on the three concentrations (Table S1). After five days of incubation (Table S2), the colony growth inhibition of F. graminearum ranged between $83 \%$ and $100 \%$. At the same time, the inhibition of $F$. proliferatum ITEM 12072 was not positively correlated to the increasing concentrations of fludioxonil (Table S2). Finally, after 10 days of incubation, all Fusarium strains were able to grow on potato dextrose agar (PDA) amended with the three fludioxonil concentrations. Inhibition values, on the highest concentration of fludioxonil, ranged between $54 \%$ and $94 \%$ for F. graminearum, $15 \%$ and $28 \%$ for $F$. proliferatum and $37 \%$ and $50 \%$ for $F$. verticillioides (Figure 1 ). Therefore, a great variability in term of sensitivity to molecule was observed among and within Fusarium species (Figure 1). Similarly, a great variability was observed within A. flavus species. At the lowest concentration, A. flavus ITEM 8095 showed an inhibition value of $24 \%$, whereas ITEM 8111 and ITEM 8115 showed inhibition values of $54 \%$ and $75 \%$, respectively (Table $\mathrm{S} 4$ ). 


\subsubsection{MBCs}

Thiophanate-methyl

Thiophanate-methyl inhibited colony growth of all Fusarium and Aspergillus species tested. Mycelial growth was fully inhibited up to 10 days of incubation, at the highest concentrations (1500 and $\left.150 \mathrm{mg} \mathrm{L}^{-1}\right)$. On PDA amended with the lowest concentration $\left(15 \mathrm{mg} \mathrm{L}^{-1}\right)$, Fusarium species showed mean values of $93 \%$ and $84 \%$, respectively (Figure 1 ).

\subsubsection{Phthalimides}

Folpet

Folpet was poorly effective to inhibit mycelyal growth of both Fusarium and A. flavus species. After three days of incubation (Table S1), only A. flavus and F. graminearum ITEM 6352 were completely inhibited at the highest concentration $\left(1200 \mathrm{mg} \mathrm{L}^{-1}\right)$. Fusarium proliferatum and F. verticillioides strains showed inhibition values ranging between $49 \%$ (F. proliferatum ITEM 12072) and $82 \%$ (F. verticillioides ITEM 12043). After 10 days, all strains tested were able to grow on PDA amended with the highest dose of the fungicide, with values ranging between $55 \%$ (F. graminearum ITEM 126 ) and $78 \%$ (A. flavus ITEM 8115).

\subsection{In Vitro Conidial Germination Inhibition}

\subsubsection{DMIs}

Aspergillus flavus strains were more inhibited than Fusarium species strains, in conidial germination. Aspergillus flavus conidia poorly germinated on media amended with the three different doses of metconazole, prothioconazole, difenoconazole, and prochloraz. On the other hand, Fusarium conidia were able to germinate on media amended with the lowest concentrations of these DMI fungicides, but after $72 \mathrm{~h}$ of incubation, the germinated conidia were completely inhibited and germ tube elongation collapsed (Table S6).

\subsubsection{SDHIs}

Boscalid inhibited completely A. flavus conidia germination at the three concentrations tested but no effects on Fusarium species were shown (Figure 2). Isopyrazam completely inhibited A. flavus conidial germination at the two highest concentrations while at the lowest concentration it inhibited the conidial germination up to $40 \%$. On the other hand, the molecule completely inhibited Fusarium conidial germination at the highest concentration, but it was ineffective at the lowest concentrations (Figure 2).

\subsubsection{PPs}

Fludioxonil was not effective towards Fusarium species conidial germination, showing a slight inhibition only at the highest concentration (maximum value inhibition of $12 \%$ for $F$. graminearum ITEM 6352). On the other hand, fludioxonil showed a good effectiveness against $A$. flavus strains, at the highest doses (mean value of $94 \%$ and $68 \%$, respectively), but it was ineffective at the lowest concentration (Figure 2). 


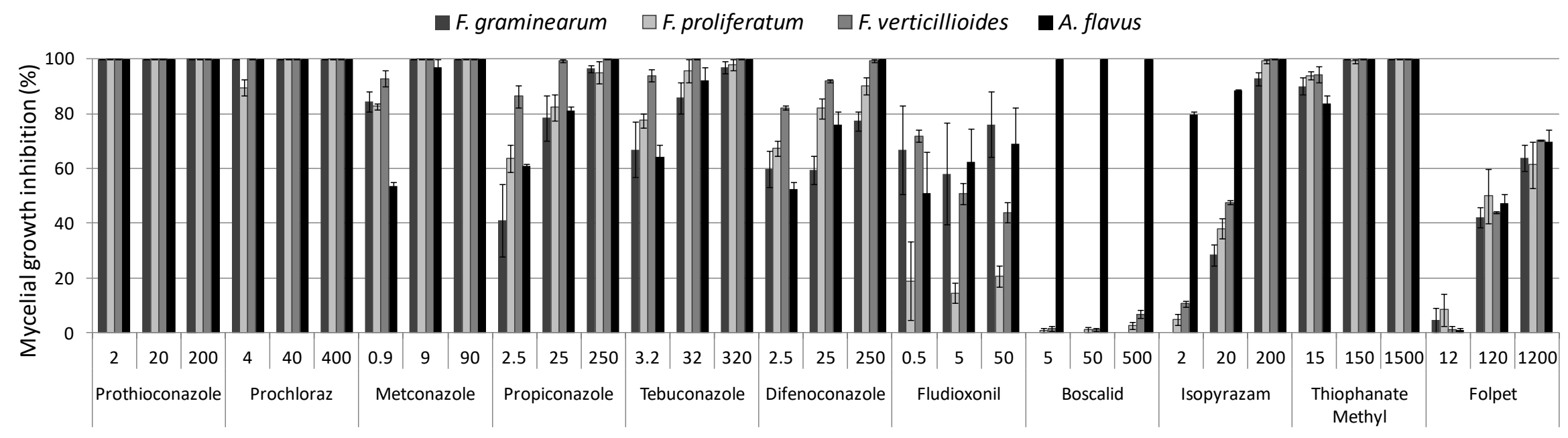

Figure 1. Colony growth inhibition on potato dextrose agar (PDA), amended with three different concentrations of fungicides (expressed in mg $\mathrm{L}^{-1}$ and reported on the x-axis), after 10 days of incubation at $25^{\circ} \mathrm{C}$. Percentage values calculated on the colony growth (expressed in mm) of the control thesis for each species, as reported in Material and Methods. 


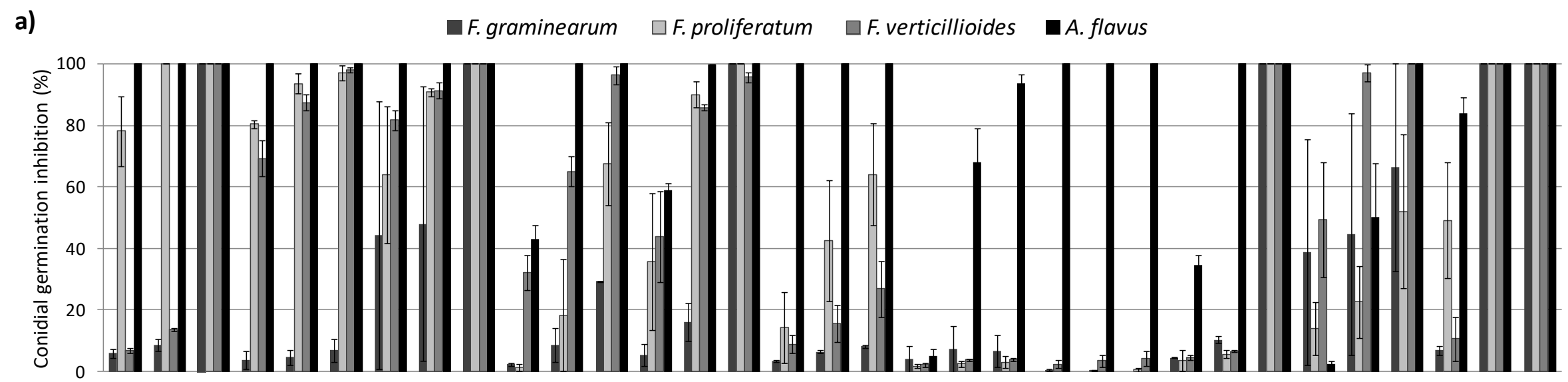

b)

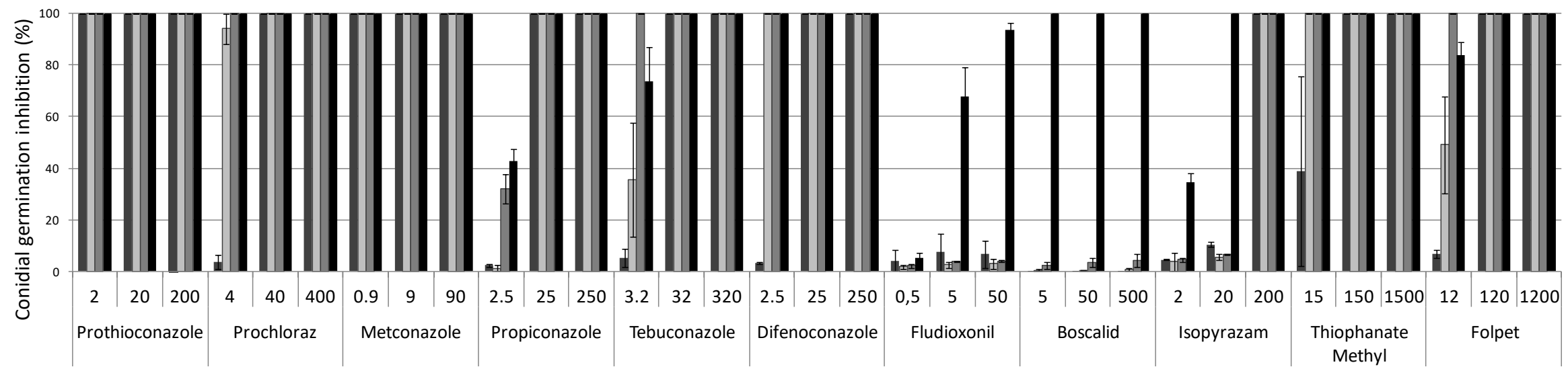

Figure 2. Conidial germination inhibition on water agar amended with three different concentrations of fungicides (expressed in $\mathrm{mg} \mathrm{L}^{-1}$ and reported on the $\mathrm{x}$-axis) (a) after $48 \mathrm{~h}$ of incubation at $25^{\circ} \mathrm{C}$ and (b) after $72 \mathrm{~h}$ of incubation at $25^{\circ} \mathrm{C}$. Percentage values calculated on the conidial germination of the control thesis for each species, as reported in Material and Methods. 


\subsubsection{MBCs}

Thiophanate-methyl showed values very variable depending on fungal strains (Table S5), fungal species and fungicide concentration (Figure 2). However, after $72 \mathrm{~h}$, all germinated conidia of $A$. flavus and Fusarium strains, except F. graminearum, at the lowest concentration (Table S5), collapsed (Figure 2). Thus, thiophanate-methyl has proved to be active to inhibit both mycelial growth and conidial germination of all strains tested.

\subsubsection{Phtalimides}

Folpet was the most active among the tested fungicides to inhibit conidial germination (100\%) already at the intermediate concentration tested (Figure 2), Folpet showed stronger inhibition towards conidial germination than mycelial growth (Figure 1). At the lowest concentration, only F. verticillioides was completely inhibited; F. graminearum, F. proliferatum and A. flavus showed mean values of $7 \%, 49 \%$, and $90 \%$, respectively.

\subsection{Fungal Symptoms Assessment on Maize Plants in Field Trials}

Infection severity mean values, measured as McKinney index (MKI), evaluated on maize plants are reported in Figure 3.

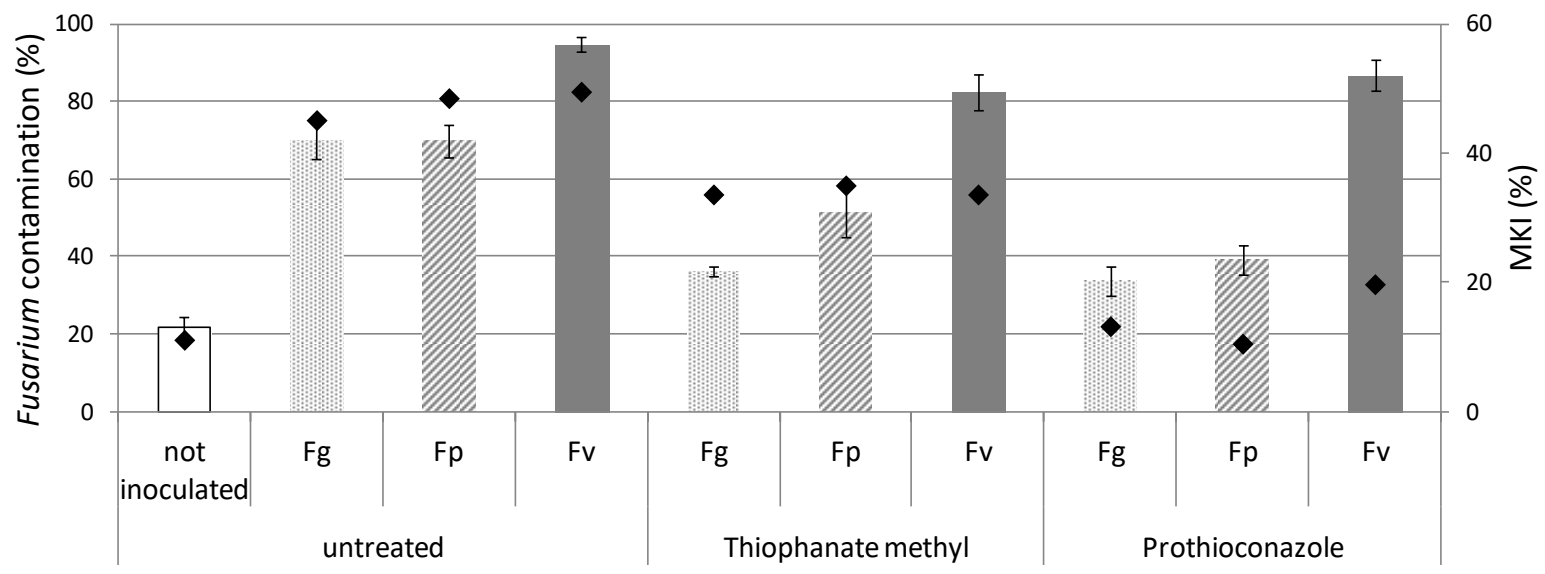

Figure 3. Fusarium contamination evaluated on maize samples not inoculated and inoculated with Fusarium graminearum (Fg), F. proliferatum (Fp), and F. verticillioides (Fv) and untreated or treated with thiophanate-methyl and prothioconazole. Error bars represent standard error among replicates. The black points show the Mc Kinney Index (MKI).

Fusarium symptoms were observed in all theses, with MKI values ranging between 10.5 (thesis inoculated with F. proliferatum and sprayed with prothioconazole) and 49.5 (thesis inoculated with F. verticillioides and untreated). Fusarium symptoms were observed even on not inoculated plants, with MKI of 11.1. Highest MKI index were detect on inoculated thesis not sprayed with fungicides (MKI of 45.1, 48.5, and 49.5 for F. graminearum, F. proliferatum, and F. verticillioides, respectively). The plants treated with prothioconazole showed the lowest MKI with a value of 13.2, 10.5, and 19.7 for F. graminearum, F. proliferatum and F. verticillioides, respectively.

Symptoms of Aspergillus infections were not observed on the maize ears.

\subsection{Re-Isolation of Fungal Species from Maize Plants by Mycological Analyses}

The fungal colonies, originated from 100 representative kernels for each field trial sample, were identified after five days of incubation, based on morphological characteristics. From samples inoculated by a given Fusarium species, the strains re-isolated belonged to the Fusarium species used 
for the inoculation; from the not inoculated and untreated samples, F. verticillioides and F. proliferatum were isolated (20\% and $2 \%$, respectively).

Fusarium contamination was detected in all the maize samples, ranging from $22 \%$ (not inoculated thesis) to 95\% (untreated thesis inoculated with F. verticillioides), as shown in Figure 3. Among Fusarium species, a different capability to colonize kernels has been observed. The lowest fungal contamination was detected in the species inoculated with F. graminearum (34-70\%). Fusarium verticillioides was detected in all theses with high contamination values, ranging between $82 \%$ and $95 \%$. Fusarium proliferatum was detected with values ranging between $39 \%$ and $70 \%$.

Contamination of Aspergillus species, mainly belonging to section Nigri (90\%), was detected in all species (data not shown). The values were $24 \%$ in not inoculated and untreated species, $15 \%$ in theses inoculated but untreated and in species treated with thiophanate-methyl, and $40 \%$ in species treated with prothioconazole. In particular, when F. graminearum was inoculated, a higher presence of Aspergillus species was detected (12\%), while when F. verticillioides was inoculated, Aspergillus contamination was negligible (0.5\%). Values of $8 \%$ were detected inoculating F. proliferatum.

In the experiment addressed to Aspergillus flavus (Figure 4), strains belonging to this species were detected in all inoculated theses, with values ranging between 7 (theses treated with boscalid), a value very similar to the not inoculated thesis (4.9\%), and 25.7 (untreated thesis). However, in all the samples, also Fusarium contamination was detected, with values ranging between $2 \%$ (theses treated with prothioconazole) and 15.5\% (untreated thesis not inoculated with A. flavus).

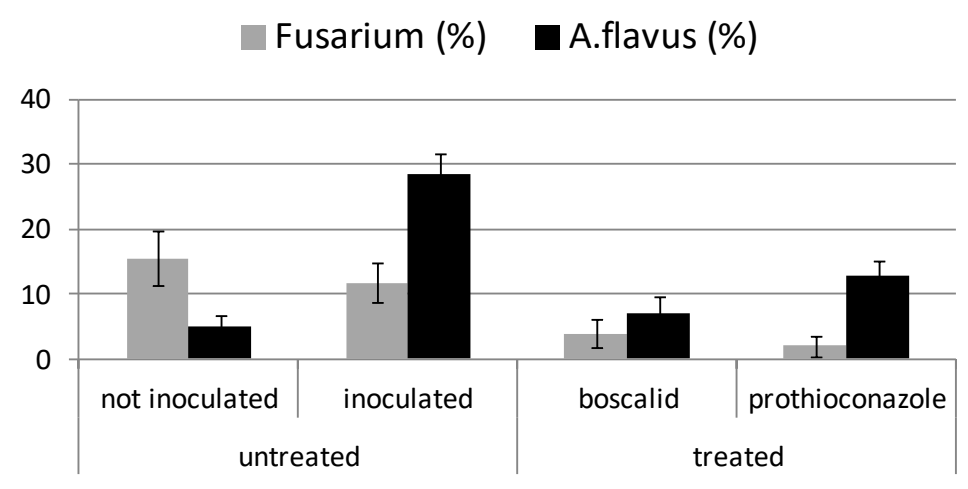

Figure 4. Aspergillus flavus contamination evaluated on maize samples inoculated and not inoculated with A. flavus in field trial. Fusarium contamination was also detected as natural contamination. Error bars represent standard error among replicates.

\section{Discussion}

This study provides new information on the sensitivity of the main toxigenic Fusarium species associated to FER of maize and A. flavus, to different fungicides. Fusarium maize ear rot is a major problem in temperate areas worldwide. In the last years, several guidelines have been suggested to optimize cropping systems in order to minimize fungal and consequent mycotoxin contamination [20]. However, when pedoclimatic conditions favorable to fungal disease development occur, direct control of fungi through use of fungicides could be an option to consider. On the other hand, chemical protection to control FER is not widely used yet and few studies have demonstrated the efficacy of synthetic fungicides on reduction of the fungal species associated to FER in maize [23,33]. Thus, studies on the effectiveness of novel fungicides, or fungicides registered on other crops, for controlling FER are highly useful. The use of different fungicides, mainly belonging to DMI compounds, is allowed to control disease associated to Fusarium species on wheat and other minor cereals [27,34]. In the present study, we tested the in vitro efficacy of eleven fungicides, belonging to DMI, SDHI, PP, MBC, and Pthalimides fungicides, among which folpet displays a multisite activity. Target-site fungicides provide several advantages when compared to multisite ones, such as a high persistence in plant 
tissues, that allows to reduce the number of treatments for crop season; higher effectiveness at lower doses; and higher selectivity against fungal pathogens [35,36].

We demonstrated that all tested DMIs reduced fungal development with higher efficacy than the other chemicals tested. However, a certain variability in their activity was observed. In particular, prothioconazole and prochloraz proved to be the most active molecules against both Fusarium species and A. flavus.

Previous studies showed that prochloraz was effective against F. culmorum and F. langsethiae [37,38]. Tebuconazole and prothioconazole showed effectiveness against a wide range of Fusarium species associated with FHB (F. avenaceum, F. culmorum, F. graminearum, F. poae, F. tricinctum, F. sporotricioides, and F. crookwellense) $[39,40]$. Moreover, the effectiveness of DMI fungicides has been demonstrated also for A. flavus strains, as reported by Formenti et al. [41], that demonstrated the sensitivity of A. flavus to prochloraz. On the other hand, the repeated use of chemicals with the same mode of action could lead to a strong selection of resistant strains. Indeed, decreased sensitivity to tebuconazole has been detected in Germany [42] and China, where DMI fungicides have been largely used in the last 30 years [32]. Since azoles are considered the most prominent fungicide class used in cereals up to date, the possible development and accumulation of resistance in fungal populations increases the need of identifying new chemicals provided of different modes of action not yet registered on maize, such as SDHI, MBC, and PP fungicides.

The recently introduced SDHI fungicides, such as boscalid and isopyrazam, have shown a great efficacy against a large spectrum of fungi [43]. However, a few years after the introduction of SDHIs, resistance has been reported in field populations and laboratory-induced mutant strains of several phytopathogenic fungi [43]. Neverthless, a not generalized cross-resistance has been observed: for instance, mepronil-resistant Rhizoctonia solani strains showed sensitivity to boscalid [44], Corynespora cassiicola and Podosphaera xanthii strains were reported to be highly resistant to boscalid but were sensitive to fluopyram [45], and field strains of Botryotinia fuckeliana were resistant to boscalid and sensitive to fluopyram [46]. In several phytopathogenic fungal species, the resistance to SDHIs has been identified in their ability to substitute some amino acids in the target proteins.

In order to better elucidate this mechanism of resistance, preliminary investigations on the molecular characterization of the four genes encoding succinate dehydrogenase subunits indicated that a high variability exists between Aspergillus and Fusarium genera, which is likely related to their different response (Masiello, data not shown).

The efficacy of some molecules belonging to SDHIs against other Fusarium species has been demonstrated in China, where F. asiaticum (a member of F. graminearum species complex [47]) strains were sensitive to the novel SDHI pydiflumetofen [48]. Moreover, in Southern Brazil, SDHIs in mixture with quinone outside inhibitors fungicides (QoI) were able to reduce F. graminearum on wheat in field conditions [49].

On the contrary, other studies demonstrated the insensitivity of F. graminearum to the SDHI isopyrazam as well as to QoI trifloxystrobin, suggesting that fungal respiration in F. graminearum seems to be significantly different from other Fusarium [50,51].

In our studies a high resistance of all Fusarium strains to boscalid and sensitivity to the highest concentration of isopyrazam were detected.

The MBC thiophanate-methyl inhibited mycelial growth and conidial germination of Fusarium species and A. flavus. In the last decades, the MBC carbendazim has been widely used to control Fusarium diseases on several plants, including wheat, tomato and cyclamen, showing a great capability to prevent Fusarium infections. However, several studies reported the occurrence of resistant field strains to MBCs $[30,35,52]$. Therefore, since thiophanate-methyl is not authorized on maize crop, and resistance issues do exist, further studies aimed to confirm its possible use in the control of toxigenic fungi on maize should be carried out.

Among PPs, fludioxonil, used alone or in mixture with other fungicides, has been largely used for cereals and soybean seed treatment, showing a high efficacy against Fusarium species [53-56]. 
We showed that all Fusarium and Aspergillus strains tested were slightly inhibited by this compound, and fungal growth inhibition was not correlate to the increasing fludioxonil concentrations. Moreover, some Fusarium strains (F. graminearum ITEM 6415, F. proliferatum ITEM 12052 and ITEM 12072, and F. verticillioides ITEM 12043 and ITEM 12044) acquired the ability to grow on fludioxonil amended media, showing sectorization of mycelium with new phenotypic traits, retained when the strains were re-inoculated on fresh PDA amended with fludioxonil, as previously reported by Broders et al. [54]. A great variability of response to fludioxonil exists among and within Fusarium species. Peters et al. [57] reported that reference strains of F. sambucinum and F. coeruleum were sensitive to fludioxonil, but all tested field strains of the same two species were resistant to fludioxonil, showing no growth inhibition up to $100 \mathrm{mg} \mathrm{L}^{-1}$ of molecule concentration. On the other hand, the efficacy of fludioxonil has been demonstrated by Ellis et al. [58], since soybean seeds treated with phthalimides captan and fludioxonil had the lowest disease severity and F. graminearum symptoms, compared to azoxystrobin use. Also, the efficacy of fludioxonil in mixture with the Phenylamides metalaxyl-M against F. verticillioides has been demonstrated by Miguel et al. [59].

The in vitro tests on molecules available on the market allowed us to select the most effective molecules against the most occurring mycotoxigenic fungi on maize. In particular, prothioconazole and thiophanate-methyl effectively inhibit Fusarium species, while prothioconazole and boscalid completely inhibit $A$. flavus (Figures 1 and 2).

Since in field conditions several variables interfere with fungal infection or disease development, subsequent experiments in field have been carried out to confirm in vitro tests. Prothioconazole confirmed the efficacy to control F. graminearum and F. proliferatum, as shown in Figure 3, showing a reduction on fungal contamination of $51 \%$ for F. graminearum and $44 \%$ for F. proliferatum, compared to untreated thesis. On the contrary, F. verticillioides contamination was similar in all the theses, suggesting a great capability of this species to colonize maize plants despite environmental conditions or chemical treatments. Moreover, if we consider the severity of fungal infection, it is very interesting to notice that MKI values of theses treated with prothioconazole are about $14 \%$, compared to $48 \%$ of inoculated untreated theses (Figure 3).

Likewise, the application of thiophanate-methyl caused a reduction of both F. graminearum and F. proliferatum of $49 \%$ and $28 \%$, respectively, while it is noneffective to control $F$. verticillioides.

Prothioconazole application on maize plants was effective also to control A. flavus, although less than Fusarium species, causing a reduction of 51\%. This species is almost completely controlled by boscalid, that reduced the contamination in kernels of $73 \%$ (Figure 4 ).

As expected, the performance of fungicides in planta showed a lower efficacy if compared to tests in vitro, although the results obtained with the two different approaches were similar. However, Fusarium contamination was detected even in plants not inoculated with Fusarium species or with A. flavus (Figures 3 and 4) and Aspergillus was detected also in the Fusarium experimental trial, probably due to cross-contamination or natural seeds contamination. Indeed, the presence of Aspergillus species, mainly belonging to section Nigri, when Fusarium infection is reduced (theses not inoculated or treated with fungicides) and vice versa, can be explained by the different ability of fungal species to compete in infecting host plants.

Probably, the tested dose of single fungicides was sublethal for fungi, since it can be suggested to increase doses to better control mycotoxigenic fungi on maize. Moreover, a further treatment, in addition to the application at flowering, could help to reduce fungal contamination during crop season. However, the mixture of fungicides with different modes of action is the best option to control the whole population of mycotoxigenic fungi occurring on maize, limiting, at the same time, the development of resistance in field strains. 


\section{Conclusions}

This study has allowed to obtain useful information about the sensitivity of $F$. graminearum, F. proliferatum, F. verticillioides, and A. flavus species, strictly associated to maize diseases and mycotoxicological risk, to the main fungicides nowadays registered on the most important crops.

In vitro experiments showed that all SDHIs had a very high efficacy against $A$. flavus, while only the highest concentration tested of isopyrazam was effective against Fusarium species. For this reason, this class of fungicides could improve the control of the main toxigenic fungi contaminating maize only if applied in mixture with molecules belonging to DMI or MBC. All DMIs, in particular prothioconazole and prochloraz, and the MBC thiophanate-methyl showed the best effectiveness to inhibit both Fusarium species and A. flavus in vitro.

The activity of the prothioconazole and thiophanate-methyl has been evaluated both in vitro and in field conditions, where several pedoclimatic and agricultural parameters could influence the host-pathogen interaction. Indeed, a different performance among Fusarium species was observed in field conditions, since $F$. verticillioides was not inhibited.

These compounds are not authorized on maize crop, and studies on their effectiveness in controlling FER and A. flavus contamination in maize field conditions are limited. Thus, this study could be useful to select the best molecules active against Fusarium and Aspergillus species associated with maize diseases, for further investigations on their feasibility.

\section{Materials and Methods}

\subsection{Fungal Strains}

The effectiveness of chemical compounds was evaluated against $F$. graminearum, F. proliferatum, F. verticillioides, and A. flavus species; for each fungal species three strains were tested. All strains were obtained from the ITEM Fungal Collection of the Institute of Sciences of Food Production, Bari (www.ispa.cnr.it/Collection). In detail, F. graminearum strains (ITEM 126, ITEM 6352, and ITEM 6415) were isolated from durum wheat in Northern Italy; F. proliferatum (ITEM 12072, ITEM 12103, and ITEM 16031), F. verticillioides (ITEM 12043, ITEM 12044, and ITEM 12052), and A. flavus strains (ITEM 8095, ITEM 8111, and ITEM 8115) were all isolated from maize kernels in Northern Italy.

All fungal strains were refreshed on Petri dishes $(90 \mathrm{~mm}$ in diameter) containing potato dextrose agar (PDA Oxoid CM0139), incubated at $25 \pm 1{ }^{\circ} \mathrm{C}$ under an alternating light/darkness cycle of $12 \mathrm{~h}$ photoperiod.

\subsection{Fungicides Tested In Vitro}

Among the most effective molecules currently used to control fungal diseases caused by ascomycetes fungi, eleven fungicides, belonging to 8 different chemical classes and showing 5 different modes of action, were tested (Table 1).

In particular, 2 fungicides-boscalid (Cantus) and isopyrazam (Zulu)—belong to SDHIs and are not registered on cereals. Six fungicides, registered on cereals, belong to DMIs: metconazole (Caramba), difenoconazole (Score25 EC), propiconazole (Opinion Ecna), and tebuconazole (Icarus EW), grouped as triazoles, the imidazoles prochloraz (Carnival) and the triazolinthiones prothioconazole (Proline). Fludioxonil (Celest) belongs to PPs, and is registered in cereals for seed coating. Thiophanate-methyl (Enovit Metil) belongs to MBCs, and folpet (Folpan80) belongs to Phtalimides fungicides; both were never registered on cereals.

The authors have mentioned the trade names of the tested fungicides for the scientific purpouse and this does not reflect any recommendation for use.

Based on dose recommended in label by manufacturers, we tested, for each fungicide, the manufacturers' suggested concentration and the two lower decimal dilutions, as reported in Table 1.

Fungicides were suspended in sterile distilled water and added to sterilized PDA or Water Agar (WA, $20 \mathrm{~g} \mathrm{~L}^{-1}$ agar Oxoid n. 3) media, cooled down to $45-50{ }^{\circ} \mathrm{C}$. 
Table 1. Fungicide tested in colony growth and conidial germination assays.

\begin{tabular}{|c|c|c|c|c|c|c|}
\hline $\begin{array}{l}\text { Commercial } \\
\text { Name }\end{array}$ & Active Ingredient & $\begin{array}{l}\text { Active Ingredient } \\
\text { Tested }\left(\mathrm{mg} \mathrm{L}^{-1}\right)\end{array}$ & Chemical Group * & Group Name * & Target Site * & Mode of Action * \\
\hline $\begin{array}{l}\text { Cantus } \\
\text { Zulu }\end{array}$ & $\begin{array}{l}\text { Boscalid } \\
\text { Isopyrazam }\end{array}$ & $\begin{array}{l}500-50-5 \\
200-20-2\end{array}$ & $\begin{array}{l}\text { pyridine-carboxamides } \\
\text { pyrazole-4-carboxamides }\end{array}$ & $\begin{array}{c}\text { SDHI (Succinate } \\
\text { dehydrogenase inhibitors) }\end{array}$ & $\begin{array}{l}\text { complex II: } \\
\text { succinate-dehydrogenase }\end{array}$ & Respiration \\
\hline $\begin{array}{l}\text { Carnival } \\
\text { Proline } \\
\text { Icarus } \\
\text { Opinion Ecna } \\
\text { Caramba } \\
\text { Score }\end{array}$ & $\begin{array}{c}\text { Prochloraz } \\
\text { Prothioconazole } \\
\text { Tebuconazole } \\
\text { Propiconazole } \\
\text { Metconazole } \\
\text { Difenoconazole }\end{array}$ & $\begin{array}{c}400-40-4 \\
200-20-2 \\
320-32-3.2 \\
250-25-2.5 \\
90-9-0.9 \\
250-25-2.5\end{array}$ & $\begin{array}{l}\text { Imidazoles } \\
\text { Triazolinthiones }\end{array}$ & $\begin{array}{l}\text { Demethylation Inhibitors SBI } \\
\text { Class I }\end{array}$ & $\begin{array}{l}\text { C14-demethylase in } \\
\text { sterol biosynthesis }\end{array}$ & $\begin{array}{l}\text { Sterol biosynthesis in } \\
\text { membranes }\end{array}$ \\
\hline Celest & Fludioxonil & $50-5-0.5$ & phenylpyrroles & $\begin{array}{l}\text { PP-fungicides } \\
\text { (PhenylPyrroles) }\end{array}$ & $\begin{array}{l}\text { MAP/Histidine-Kinase } \\
\text { in osmotic signal } \\
\text { transduction }\end{array}$ & signal transduction \\
\hline Enovit Metil FL & Thiophanate-methyl & 1500-150-15 & Thiophanates & $\begin{array}{l}\text { MBC-Fungicides (Methyl } \\
\text { Benzimidazole Carbamates) }\end{array}$ & $\begin{array}{l}\beta \text {-tubuline assembly } \\
\text { in mitosis }\end{array}$ & $\begin{array}{l}\text { mitosis and cell } \\
\text { division }\end{array}$ \\
\hline Folpan80 & Folpet & $1200-120-12$ & phthalimides & Phthalimides & $\begin{array}{l}\text { multisite contact } \\
\text { activity }\end{array}$ & $\begin{array}{l}\text { Multisite contact } \\
\text { activity }\end{array}$ \\
\hline
\end{tabular}




\subsection{Mycelial and Conidial Germination Assays}

The activity of fungicides against the fungal strains was evaluated by measuring colony growth and conidial germination.

Each fungicide was suspended in distilled sterile water to obtain three different concentrations to be tested. The highest concentration was prepared in order to represent the effective dose of the active ingredient, recommended by the manufacturer for field treatments; the subsequent two concentrations were in a ratio 1:10 to each other. Appropriate volumes of liquid fungicides were added to sterile PDA cooled down to $45-50{ }^{\circ} \mathrm{C}$, in order to obtain the concentrations shown in Table 1. Each active ingredient was tested in three concentrations against fungal species strains, in triplicate. In the control theses only PDA was used.

In mycelial growth assay, mycelium disks (4 $\mathrm{mm}$ in diameter) from actively growing margins of 3-5 day old colonies cultured on PDA, were used to inoculate Petri dishes ( $90 \mathrm{~mm}$ in diameter) containing PDA or PDA amended with fungicides. The inhibition activity of the fungicide on colony growth was determined by measuring the diameter (in $\mathrm{mm}$ ) of developing colonies after 3, 5, 7, and 10 days of incubation at $25 \pm 1{ }^{\circ} \mathrm{C}$, under an alternating light/darkness cycle of $12 \mathrm{~h}$ photoperiod. A ruler was used to measure the two orthogonal diameters of the colony. The inhibition caused by each fungicide concentration was expressed as percentage value, reporting the difference between the maximum level of inhibition with no growth of the fungal colony on the medium $(100 \%)$, and the ratio between diameter of colony growth on PDA amended with the fungicide and the diameter of the growth of colony inoculated on PDA medium as control (value of $0 \%$ means the total lack of inhibition corresponding to full growth of the fungal colony on the medium). The mean values obtained from the three tested strains were reported for each species.

In conidial germination test, conidia were collected by scraping the surface of 7-day-old colonies, grown on PDA at $25 \pm 1{ }^{\circ} \mathrm{C}$ under an alternating light/darkness cycle of $12 \mathrm{~h}$ photoperiod, with a sterilized loop, suspended in sterile distilled water containing $0.05 \%$ Tween 20 , and filtered through Miracloth (Calbiochem, La Jolla, Canada) to remove mycelia fragments. Aliquots $(10 \mu \mathrm{L})$ of conidial suspension $\left(1 \times 10^{5}\right.$ conidia $\left.\mathrm{mL}^{-1}\right)$ were spotted on disks $(6 \mathrm{~mm}$ diam) of WA medium and WA amended with fungicides ( 3 concentrations, as reported above for mycelium growth experiments) placed on sterile microscope slides. The disks were incubated in a moist chamber at $25 \pm 1{ }^{\circ} \mathrm{C}$ in darkness and after $48 \mathrm{~h} ; 100$ conidia randomly selected on each of three replicated spots were observed at optical microscope with $125 \times$ magnification, germinated conidia were counted. After $72 \mathrm{~h}$, the ability of conidia to growth was confirmed observing the germ tube elongation. The frequency of conidia able to germinate on medium amended with fungicide was calculated considering the frequency of conidia germination on the untreated control medium. The mean values obtained from the three tested strains were reported for each species.

\subsection{Field Experiments Settings}

Based on in vitro test results, the most effective fungicides were selected to set experiments on maize plants in field. Prothioconazole, as representative of DMIs, and the MBC thiophanate-methyl were tested against F. graminearum, F. proliferatum, and F. verticillioides; prothioconazole and boscalid (SDHI) against $A$. flavus.

Uncoated seeds of the commercial maize variety "Marano 0501" were selected for the experiment. A representative seed sub-sample was previously analyzed to confirm the low Fusarium and Aspergillus species contamination, in order to exclude possible source of fungal contamination during experimental trial.

Two experimental trials were separately set up to test the effectiveness of fungicide application during flowering stage against Fusarium species and A. flavus.

For each fungal species 4 different theses were compared, including a negative control (plants not inoculated), a positive control (plants inoculated and untreated), and two theses treated with the two selected fungicides. Each thesis consisted of 24 maize plants, in particular, 3 replicates of 8 plants 
were considered, following a randomized block experimental design. Each plot, of $125 \times 210 \mathrm{~cm}$, was separated by a border line plants in order to exclude cross contamination. The experimental designs used for Fusarium and Aspergillus trials are detailed in Figures S1 and S2.

\subsubsection{Fungicide Application and Fungal Inoculum}

Two days before fungal inoculation, each plot, each well separated with plastic films in order to exclude cross contamination, was sprayed with fungicide arranging the dose recommended by manufacturers for other crops: $0.8 \mathrm{~L} / \mathrm{Ha}$ for prothioconazole (Proline), $1.25 \mathrm{~L} / \mathrm{Ha}$ for thiophanate-methyl (Enovit Methyl), and $1 \mathrm{Kg} / \mathrm{Ha}$ for boscalid (Cantus).

In pre-flowering time, conidial suspensions in sterile water containing $10^{-5}$ conidia $\mathrm{mL}^{-1}$ of each Fusarium and Aspergillus species were prepared by scraping the surface of 7-day-old colonies grown on PDA, and then stored at $4{ }^{\circ} \mathrm{C}$ until use. At flowering time and two day after fungicide application, $500 \mu \mathrm{L}$ of each conidial suspension were sprayed, according to the planned theses, on flowery silks of each maize ear, by using an atomizer.

\subsubsection{Evaluation of Fungal Symptoms on Maize Plants}

At harvesting time, symptoms of fungal infections on maize plants were assessed according to an empirical scale with seven classes of severity, from 0 (absence of infections) to 6 (extensive symptoms of infection closed to $100 \%$ of plant surface). Infection severity was calculated by McKinney Index (MKI).

\subsubsection{Fungal Re-isolation and Growth Conditions}

At harvesting time, each plot consisting of 8 maize plants was harvested and stored at $4{ }^{\circ} \mathrm{C}$. For each sample, 100 representative kernels were superficially disinfected in a $2 \%$ sodium hypochlorite solution for $2 \mathrm{~min}$, washed twice with sterile distilled water for one minute and then plated (10 kernels/plate) on PDA added with pentachloronitrobenzene (PCNB; $500 \mathrm{mg} \mathrm{L}^{-1}$ ), streptomycin $\left(100 \mathrm{mg} \mathrm{L}^{-1}\right)$, and neomycin $\left(50 \mathrm{mg} \mathrm{L}^{-1}\right)$. After 5 days of incubation at $25^{\circ} \pm 1{ }^{\circ} \mathrm{C}$ under fluorescent light (12 h photoperiod), the contamination of the inoculated fungal species was detected for each sample. In addition, in the samples inoculated with A. flavus, both $A$. flavus and Fusarium contamination was evaluated, in order to evaluate the effectiveness of fungicides against the natural Fusarium contamination occurring on maize seeds.

Supplementary Materials: The following are available online at http:/ /www.mdpi.com/2072-6651/11/1/11/s1, Table S1: Colony growth inhibition on PDA amended with three different concentrations of active ingredient (A.i.) for each fungicide, after 3 days of incubation at $25^{\circ} \mathrm{C}$, Table S2: Colony growth inhibition on PDA amended with three different concentrations of active ingredient (A.i.) for each fungicide, after 5 days of incubation at $25^{\circ} \mathrm{C}$, Table S3: Colony growth inhibition on PDA amended with three different concentrations of active ingredient (A.i.) for each fungicide, after 7 days of incubation at $25^{\circ} \mathrm{C}$, Table S4: Colony growth inhibition on PDA amended with three different concentrations of active ingredient (A.i.) for each fungicide, after 10 days of incubation at $25{ }^{\circ} \mathrm{C}$, Table S5: Conidial germination inhibition on water agar amended with three different concentrations of active ingredient (A.i.) for each fungicide, after $48 \mathrm{~h}$ of incubation at $25^{\circ} \mathrm{C}$, Table S6: Conidial germination inhibition on water agar amended with three different concentrations of active ingredient (A.i.) for each fungicide, after $72 \mathrm{~h}$ of incubation at $25^{\circ} \mathrm{C}$, Figure S1: Randomized block experimental design used in the field experiment trial to test the effectiveness of prothioconazole (Pro) and thiophanate-methyl (ThM) treatments compared to untreated theses inoculated with Fusarium graminearum (FG), F. proliferatum (FP) and F. verticillioides (FV) strains. Untreated and not inoculated thesis (NC) was also included, Figure S2: Randomized block experimental design used in the field experiment trial to test the effectiveness of prothioconazole (Pro) and boscalid (Bos) treatments compared to untreated theses inoculated with Aspergillus flavus (AF). Untreated and not inoculated thesis (NC) was also included.

Author Contributions: Conceptualization, M.M. and A.M.; Methodology, M.M.; Validation, V.G., M.M., and S.S.; Formal Analysis, M.M. and S.S; Investigation, V.G., M.M., and S.S.; Resources, V.G., A.F.L., M.M., A.M., and S.S.; Data Curation, M.M. and S.S.; Writing-Original Draft Preparation, M.M., A.M., and S.S.; Writing-Review \& Editing, A.F.L. and A.M.; Visualization, M.M. and S.S.; Supervision, A.M.; Project Administration, A.M.; Funding Acquisition, A.F.L.

Funding: This research received no external funding. 
Acknowledgments: This work was supported by H2020-E.U.3.2-678781-MycoKey-Integrated and innovative key actions for mycotoxin management in the food end feed chain.

Conflicts of Interest: The authors declare no conflicts of interest.

\section{References}

1. FAOSTAT. Available online: www.fao.org/faostat/en (accessed on 11 November 2018).

2. Latterell, F.M.; Rossi, A.E. Gray leaf spot of corn: A disease on the move. Plant Dis. 1983, 67, $842-847$. [CrossRef]

3. Leslie, J.F.; Pearson, C.A.S.; Nelson, P.E.; Toussoun, T.A. Fusarium spp. from corn, sorghum and soybean fields in the central and eastern United States. Phytopathology 1990, 80, 343-350. [CrossRef]

4. Zhang, B.; Chen, W.; Yang, X. Occurrence of Pythium species in long-term maize and soybean monoculture and maize/soybean rotation. Mycol. Res. 1998, 102, 1450-1452. [CrossRef]

5. White, D.G. Compendium of Corn Disease, 3rd ed.; American Phytopathological Society: St. Paul, MN, USA, 1999; ISBN 0890542341.

6. Treikale, O.; Javoisha, B.; Pugacheva, E.; Vigule, Z.; Feodorova-Fedotova, L. Northern leaf blight Helminthosporium turcicum on maize in Latvia. Commun. Agric. Appl. Biol. Sci. 2014, 79, 481-485. [PubMed]

7. Munkvold, G.P. Epidemiology of Fusarium disease and their mycotoxins in maize ears. Eur. J. Plant Pathol. 2003, 109, 705-713. [CrossRef]

8. Brefort, T.; Doehlemann, G.; Mendoza-Mendoza, A.; Reissmann, S.; Djamei, A.; Kahmann, R. Ustilago maydis as a Pathogen. Annu. Rev. Phytopathol. 2009, 47, 423-445. [CrossRef]

9. Vollmeister, E.; Schipper, K.; Baumann, S.; Haag, C.; Pohlmann, T.; Stock, J.; Feldbrügge, M. Fungal development of the plant pathogen Ustilago maydis. FEMS Microbiol. Rev. 2012, 36, 59-77. [CrossRef]

10. Logrieco, A.F.; Mulè, G.; Moretti, A.; Bottalico, A. Toxigenic Fusarium species and mycotoxins associated with maize ear rot in Europe. In Mycotoxins in Plant Disease; Logrieco, A., Bailey, J.A., Corazza, L., Cooke, B.M., Eds.; Kluwer Academic Publishers: Dordrecht, The Netherlands, 2002; pp. 597-609. ISBN 0-4020-0871-6.

11. Logrieco, A.; Moretti, A.; Perrone, G.; Mulè, G. Biodiversity of complexes of mycotoxigenic fungal species associated with Fusarium ear rot of maize and Aspergillus rot of grape. Int. J. Food Microbiol. 2007, 119, 11-16. [CrossRef]

12. Desjardins, A.E. Fusarium Mycotoxins. Chemistry, Genetics, and Biology; APS Press: St. Paul, MN, USA, 2006; ISBN 9780890543351.

13. Escobar, J.; Lorán, S.; Giménez, I.; Ferruz, E.; Herrera, M.; Herrera, A.; Ariño, A. Occurrence and exposure assessment of Fusarium mycotoxins in maize germ, refined corn oil and margarine. Food Chem. Toxicol. 2013, 62, 514-520. [CrossRef]

14. De Boevre, M.; Jacxsens, L.; Lachat, C.; Eeckhout, M.; Di Mavungu, J.D.; Audenaert, K.; Maene, P.; Haesaert, G.; Kolsteren, P.; De Meulenaer, B.; et al. Human exposure to mycotoxins and their masked forms through cereal-based foods in Belgium. Toxicol. Lett. 2013, 218, 281-292. [CrossRef]

15. Sekiyama, B.L.; Ribeiro, A.B.; Machinski, P.A.; Machinski, M. Aflatoxins, ochratoxins and zearalenone in maize-based food products. Braz. J. Microbiol. 2005, 36, 289-294. [CrossRef]

16. IARC. Some naturally occurring substances: Food ITEMs and constituents, heterocyclic aromatic amines and mycotoxins. In IARC Monographs on the Evaluation of Carcinogenic Risks to Human; IARC: Lyon, France, 1993; Volume 56, pp. 245-395. ISBN 92-832-1256-8.

17. Logrieco, A.; Bottalico, A.; Mulè, G.; Moretti, A.; Perrone, G. Epidemiology of toxigenic fungi and their associated mycotoxins for some Mediterranean crops. Eur. J. Plant Pathol. 2003, 109, 645-667. [CrossRef]

18. Balazs, E.; Schepers, J.S. The Mycotoxin Threat to Food Safety. Int. J. Food Microbiol. 2007, 119, 1-2. [CrossRef] [PubMed]

19. EFSA (European Food Safety Authority). Evaluation of the increase of risk for public health related to a possible temporary derogation from the maximum level of deoxynivalenol, zearalenone and fumonisins for maize and maize products. EFSA J. 2014, 12, 3699. [CrossRef]

20. Blandino, M.; Scarpino, V.; Giordano, D.; Sulyok, M.; Krska, R.; Vanara, F.; Reyneri, A. Impact of sowing time, hybrid and environmental condition of maize by emerging mycotoxins and fungal metabolites. Ital. J. Agron. 2017, 12, 928. [CrossRef] 
21. Battilani, P.; Toscano, P.; Van der Fels-Klerx, H.J.; Moretti, A.; Camardo Leggieri, M.; Brera, C.; Rortais, A.; Goumperis, T.; Robinson, T. Aflatoxin B1 contamination in maize in Europe increases due to climate change. Sci. Rep. 2016, 6, 24328. [CrossRef]

22. Munkvold, G.P. Mycotoxins in corn: Occurrence, impacts, and management. In Corn Chemistry and Technology, 2nd ed.; White, P., Johnson, L., Eds.; American Association of Cereal Chemist: St. Paul, MI, USA, 2003; pp. 811-881.

23. Folcher, L.; Jarry, M.; Weissenberger, A.; Gérault, F.; Eychenne, N.; Delos, M.; Regnault-Roger, C. Comparative activity of agrochemical treatments on mycotoxin level with regard to corn borers and Fusarium mycoflora in maize (Zea mays L.) fields. Crop Prot. 2009, 28, 302-308. [CrossRef]

24. Mesterhazy, A.; Lemmens, M.; Reid, L.M. Breeding for resistance to ear rots caused by Fusarium spp. in maize-A review. Plant Breed. 2012, 131, 1-19. [CrossRef]

25. Blandino, M.; Reyneri, A.; Vanara, F.; Ferrero, C. Control of mycotoxins in corn from harvesting to processing operation. In Proceedings of the International Quality Grains Conference, Indianapolis, Indiana, IN, USA, 19-22 July 2004.

26. Abdallah, M.F.; Ameye, M.; De Saeger, S.; Audenaert, K.; Haesaert, G. Biological control of mycotoxigenic fungi and their toxins: An update for the pre-harvest approach. In Fungi and Mycotoxins-Their Occurrence, Impact on Health and the Economy as Well as Pre-and Postharvest Management Strategies; Berka Njobeh, P., Ed.; IntechOpen: London, UK, 2018.

27. Blandino, M.; Reyneri, A. Effect of fungicide and foliar fertilizer application to winter wheat at anthesis on flag leaf senescence, grain yield, flour bread-making quality and DON contamination. Eur. J. Agron. 2009, 30, 275-282. [CrossRef]

28. De Curtis, F.; Haidukowsky, M.; Moretti, A.; Castoria, R.; Lima, G.; Pascale, P. Occurence of Fusarium ear rot and fumonisin contamination of maize in Molise and effects of synthetic fungicides. J. Plant Pathol. 2008, 90, 371-376.

29. Wang, J.X.; Zhou, M.G. Methods for monitoring resistance of Gibberella zeae to carbendazim. Acta Phytophylacica Sin. 2002, 29, 73-77.

30. Chen, C.J.; Wang, J.X.; Luo, Q.Q.; Yuan, S.K.; Zhou, M.G. Characterization and fitness of carbendazim-resistant strains of Fusarium graminearum (wheat scab). Pest Manag. Sci. 2007, 63, 1201-1207. [CrossRef] [PubMed]

31. Chen, Y.; Zhou, M.G. Characterization of Fusarium graminearum isolates resistant to both carbendazim and a new fungicide JS399-19. Phytopathology 2009, 99, 441-446. [CrossRef] [PubMed]

32. Yin, Y.; Liu, X.; Li, B.; Ma, Z. Characterization of steroldemethylation inhibitor-resistant isolates of Fusarium asiaticum and F. graminearum collected from wheat in China. Phytopathology 2009, 99, 487-497. [CrossRef] [PubMed]

33. Mazzoni, E.; Scandolara, A.; Giorni, P.; Pietri, A.; Battilani, P. Field control of Fusarium ear rot, Ostrinia nubilalis (Hübner) and fumonisins in maize kernels. Pest Manag. Sci. 2011, 67, 458-465. [CrossRef] [PubMed]

34. Edwards, S.G.; Pirgozliev, S.R.; Hare, M.C.; Jenkinson, P. Quantification of trichothecene-producing Fusarium species in harvest grain by competitive PCR to determine the efficacy of fungicides against Fusarium head blight of winter wheat. Appl. Environ. Microbiol. 2001, 67, 1575-1580. [CrossRef] [PubMed]

35. Brent, K.J.; Hollomon, D.W. Fungicide Resistance: The Assessment of Risk. In Global Crop Protection Federation. (FRAC Monograph No. 2.); The Fungicide Resistance Action Committee Brussels: Brussels, Belgium, 2007.

36. Hewitt, G. New modes of action of fungicides. Pestic. Outlook 2000, 11, 28-32. [CrossRef]

37. Doohan, F.M.; Nicholson, P.; Parry, D.W. Efficacy of the fungicides prochloraz and pyrimethanil against Fusarium culmorum ear blight of wheat. In Proceedings of the International Conference: Pests \& Diseases, Brighton, UK, 18-21 November 1996; pp. 409-410.

38. Mateo, E.M.; Valle-Algarra, F.M.; Mateo, R.; Jimenez, M.; Magan, N. Effect of fenopropimorph, prochloraz and tebuconazole on growth and production of T-2 and HT-2 toxins by Fusarium langsethiae in oat-based medium. Int. J. Food Microbiol. 2011, 151, 289-298. [CrossRef]

39. Mullenborn, C.; Steiner, U.; Ludwig, M.; Oerke, E.C. Effect of fungicides on the complex of Fusarium species and saprophytic fungi colonizing wheat kernels. Eur. J. Plant Pathol. 2008, 120, 157-166. [CrossRef]

40. Audenaert, K.; Callewaert, E.; Höfte, M.; De Saeger, S.; Haesaert, G. Hydrogen peroxide induced by the fungicide prothioconazole triggers deoxynivalenol (DON) production by Fusarium graminearum. BMC Microbiol. 2010, 10, 112. [CrossRef] 
41. Formenti, S.; Magan, N.; Pietri, A.; Battilani, P. In Vitro impact on growth, fumonisins and aflatoxins production by Fusarium verticillioides and Aspergillus flavus using anti-fungal compounds and a biological control agent. Phytopathol. Mediterr. 2012, 51, 247-256. [CrossRef]

42. Klix, M.B.; Verreet, J.A.; Beyer, M. Comparison of the declining triazole sensitivity of Gibberella zeae and increased sensitivity achieved by advances in triazole fungicide development. Crop Prot. 2007, 26, 683-690. [CrossRef]

43. Avenot, H.F.; Michailides, T.J. Progress in understanding molecular mechanisms and evolution of resistance to succinate dehydrogenase inhibiting (SDHI) fungicides in phytopathogenic fungi. Crop Prot. 2010, 29, 643-651. [CrossRef]

44. Zhang, C.Q.; Liu, Y.H.; Ma, X.Y.; Feng, Z.; Ma, Z.H. Characterization of sensitivity of Rhizoctonia solani, causing rice sheath blight, to mepronil and boscalid. Crop Prot. 2009, 28, 381-386. [CrossRef]

45. Ishii, H.; Miyamoto, T.; Ushio, S.; Kakishima, M. Lack of cross-resistance to a novel succinate dehydrogenase inhibitor, fluopyram, in highly boscalid-resistant isolates of Corynespora cassiicola and Podosphaer axanthii. Pest Manag. Sci. 2011, 67, 474-482. [CrossRef] [PubMed]

46. De Miccolis Angelini, R.M.; Masiello, M.; Rotolo, C.; Pollastro, S.; Faretra, F. Molecular characterization and detection of resistance to succinate dehydrogenase inhibitor fungicides in Botryotinia fuckeliana (Botrytis cinerea). Pest Manag. Sci. 2014, 70, 1884-1893. [CrossRef] [PubMed]

47. O'Donnell, K.; Ward, T.J.; Geiser, D.M.; Kistler, H.C.; Aoki, T. Genealogical concordance between mating type locus and seven other nuclear genes supports formal recognition of nine phylogenetically distinct species within the Fusarium graminearum clade. Fungal Genet. Biol. 2004, 41, 600-623. [CrossRef]

48. Hou, Y.P.; Mao, X.W.; Wang, J.X.; Zhan, S.W.; Zhou, M.G. Sensitivity of Fusarium asiaticum to a novel succinate dehydrogenase inhibitor fungicide pydiflumetofen. Crop Prot. 2017, 96, 237-244. [CrossRef]

49. Marques, L.N.; Pizzutti, I.R.; Balardin, R.S.; Dos Santos, I.D.; Dias, J.V.; Stefanello, M.T.; Serafini, P.T. Occurrence of mycotoxins in wheat grains exposed to fungicides on Fusarium head blight control in southern Brazil. J. Environ. Sci. Health B 2017, 52, 244-250. [CrossRef]

50. Dubos, T.; Pasquali, M.; Pogoda, F.; Casanova, A.; Hoffmann, L.; Beyer, M. Differences between the succinate dehydrogenase sequences of isopyrazam sensitive Zymoseptoria tritici and insensitive Fusarium graminearum strains. Pestic. Biochem. Phys. 2013, 105, 28-35. [CrossRef]

51. Dubos, T.; Pasquali, M.; Pogoda, F.; Hoffmann, L.; Beyer, M. Evidence for natural resistance towards trifloxystrobin in Fusarium graminearum. Eur. J. Plant Pathol. 2011, 130, 239-248. [CrossRef]

52. O'Neill, T.M. Evaluation of fungicides against fusarium wilt (Fusarium oxysporum f.sp. cyclaminis) of cyclamen. Tests Agrochem. Cultiv. 1995, 16, 20-21.

53. Munkvold, G.P.; O'Mara, J.K. Laboratory and Growth Chamber Evaluation of Fungicidal Seed Treatments for Maize Seedling Blight Caused by Fusarium Species. Plant Dis. 2002, 86, 143-150. [CrossRef]

54. Broders, K.D.; Lipps, P.E.; Paul, P.A.; Dorrance, A.E. Evaluation of Fusarium graminearum associated with corn and soybean seed and seedling disease in Ohio. Plant Dis. 2007, 91, 1155-1160. [CrossRef]

55. Munkvold, G.P.; Watrin, C.; Scheller, M.; Zeun, R.; Olaya, G. Benefits of Chemical Seed Treatments on Crop Yield and Quality. In Global Perspectives on the Health of Seeds and Plant Propagation Material. Plant Pathology in the 21st Century; Gullino, M., Munkvold, G., Eds.; Springer: Heidelberg, Germany, 2014; Volume 6, pp. 89-103.

56. Sooväli, P.; Koppel, M.; Kangor, T. Effectiveness of seed treatment against Fusarium spp. and Cochliobolus sativus of spring barley in different conditions. Agron. Res. 2017, 15, 280-287.

57. Peters, R.D.; Platt, H.W.; Drake, K.A.; Coffin, R.H.; Moorehead, S.; Clark, M.M.; Al-Mughrabi, K.I.; Howard, R.J. First Report of Fludioxonil-Resistant Isolates of Fusarium spp. Causing Potato Seed-Piece Decay. Plant Dis. 2008, 92, 172. [CrossRef]

58. Ellis, M.L.; Broders, K.D.; Paul, P.A.; Dorrance, A.E. Infection of Soybean Seed by Fusarium graminearum and Effect of Seed Treatments on Disease Under Controlled Conditions. Plant Dis. 2011, 95, 401-407. [CrossRef]

59. Miguel, T.A.; Bordini, J.G.; Saito, G.H.; Andrade, C.G.T.J.; Ono, M.A.; Hirooka, E.Y.; Vizoni, E.; Ono, E.Y.S. Effect of fungicide on Fusarium verticillioides mycelia morphology and fumonisin B1 production. Braz. J. Microbiol. 2015, 46, 293-299. [CrossRef] [PubMed]

(C) 2019 by the authors. Licensee MDPI, Basel, Switzerland. This article is an open access article distributed under the terms and conditions of the Creative Commons Attribution (CC BY) license (http:/ / creativecommons.org/licenses/by/4.0/). 